\title{
The Relationship Between Economic Freedom And Income Equality In The United States
}

Allen L Webster, Ph.D., Bradley University, USA

\begin{abstract}
While considerable research in the past has focused on the socioeconomic impact of economic freedom on economic growth among nations, less emphasis has been devoted to the relationship between economic sovereignty and income equality. This is particularly true when the area of focus has been restricted to comparisons among states within the United States. Furthermore, what work has been offered comparing US states has proven to be contradictory. Certain studies reviewed in this paper suggest that higher measures of economic freedom are associated with greater income inequality. On the other hand, evidence exists that less inequality is found in areas with greater economic autonomy. This study uses the Gini Index as measures of income distribution. The Fraser Institute in Vancouver, Canada offers well-respected measures of economic freedom among the US states and the provinces of Canada. These data are used to further examine relationships between state levels of economic freedom and income distribution with the intent to offer some general consensus regarding this all-important association.
\end{abstract}

Keywords: Economic Freedom and Income Equality; Economic Freedom and Income Equality

\section{INTRODUCTION}

s economic uncertainty continues to plague our national interests passionate debate rages as to the proper course of action that should be taken to forestall what many see as an impending economic catastrophe. On the one hand, ardent disputants call for stricter government intervention to right the
economy. They contend that only through central direction can progress toward a more equitable and fair-minded society be accomplished. At the other extreme, the outcry for greater economic liberty can be heard. This argument holds forth that economic freedom will offer the wherewithal to promote economic growth and prosperity.

The dispute centers on the proper degree of economic sovereignty that should prevail in order to promote optimal economic results. The manner in which economic freedom is measured is essential to any empirical study of social and economic liberties. Fortunately, useful standards of economic freedom have been developed by the Fraser Institute, an independent non-profit research and educational organization with the stated mandate "to measure, study, and communicate the impact of competitive markets and government intervention on the welfare of individuals." James Gwartney holds the Gus A. Stavros Eminent Scholar Chair at Florida State University where he directs the Stavros Center for the Advancement of Free Enterprise and Economic Education. Under his direction and that of other research specialists, the Institute prepares an annual index of the degree of economic freedom enjoyed by many nations throughout the globe. This annual report, entitled the Economic Freedom of World, can be accessed at www.freetheworld.com and offers a wealth of information and data regarding the important issues surrounding economic liberties.

In similar fashion, the Fraser Institute also offers another annual report identified as the Economic Freedom of North America (Bueno, Ashby and McMahon, 2012). Just as Economic Freedom of the World seeks to measure economic freedom on an international basis, the Economic Freedom of North America measures differences in economic freedom between the Canadian provinces and U.S. states. It is this latter publication that is used in this present research. 
The indices of economic freedom used by the Fraser Institute focus on three main areas of concern. Each area contains subcategories as shown in Table 1. Each of the areas and their subcategories are largely selfexplanatory. However, certain select entries may require further explanation. For example, "Takings and Discretionary Taxation" simply refers to the revenue governments acquire through direct taxation. Discretionary taxation applies only to those individuals engaging in a particular activity. For example, sales taxes indicated in subcategory $2 \mathrm{D}$ refer only to transactions involving taxable retail purchases.

Table 1 - The Areas and Components of the Economic Freedom of North America Index

\begin{tabular}{|l|}
\hline \hline 1. Size of Government \\
\hline 1A. General Consumption Expenditures by Government as a Percentage of GDP \\
\hline 1B. Transfers and Subsidies as a Percentage of GDP \\
\hline 1C: Social Security Payments as a Percentage of GDP \\
\hline \hline 2. Takings and Discriminatory Taxation \\
\hline 2A. Total Government Revenue from Own Source as a Percentage of GDP \\
\hline 2B. Top Marginal Income Tax Rate and the Income Threshold at Which It Applies \\
\hline 2C. Indirect Tax Revenue as a Percentage of GDP \\
\hline 2D. Sales Taxes Collected as a Percentage of GDP \\
\hline 3. Labor Market Freedom \\
\hline 3A. Minimum Wage Legislation \\
\hline 3B. Government Employment as a Percentage of Total State/Provincial Employment \\
\hline 3C: Union Density \\
\hline
\end{tabular}

Each index is based on a scale from 0 to 10 , with 10 indicating the highest degree of economic liberty. The overall index is compiled as an unweighted average of the three primary areas. A more complete description of the items used to generate the indices can be obtained from any of the annual reports provided by the Fraser Institute.

The indices published by the Institute measure economic freedom at two levels: the sub-national and the all-government. The sub-national level refers to the provincial and municipal governments in Canada and the state and local governments in the United States. At the all-government level the impact of federal governments is also measured. All 50 states in the U. S. and the 10 provinces in Canada are included in the Institute's reports. This paper relies only on data from the 50 U.S. states.

A simple mathematical formula to reduce subjective judgments was constructed by the Institute to represent the underlying distribution of the components in the index. The index is a relative ranking. The index assigns a higher score when, for example, component 1A, General Consumption Expenditures by Government as a Percentage of GDP, is smaller in one state or province relative to another. The rating formula is consistent across time to allow an examination of the evolution of economic freedom. In order to construct the overall index without imposing subjective judgments about the relative importance of the components, each area was equally weighted and each component within each area was equally weighted.

Again, to avoid subjective judgments, objective methods were used to calculate and weigh the components. For all components, each observation was transformed into a number from zero to 10 using the formula

$$
\left[\frac{V_{\max }-V_{i}}{V_{\max }-V_{\min }}\right] * 10
$$

where $\mathrm{V}_{\max }$ is the largest value found within a component, $\mathrm{V}_{\min }$ is the smallest, and $\mathrm{V}_{\mathrm{i}}$ is the observation to be transformed. For each component, the calculation includes all data for all years to allow comparisons over time. To transform the individual components into the three areas as well as the overall summary index, Areas 1,2, and 3 were equally weighted, and each of the components within each area are equally weighted. For example, the weight for Area 1 was 33.3\%. Area 1 has three components, each of which receives equal weight in calculating Area 1, and $11.1 \%$ in calculating the overall index. 


\section{LITERATURE REVIEW}

Earlier studies designed to detect the relationship between levels of economic freedom and economic prosperity have produced discordant results. Both Berggren (1999) and Scully (2002) for example offer evidence that higher levels of economic freedom are concordant with a more positive economic climate, especially as it relates to greater degrees of income equality. Berggren concludes that a positive change in economic freedom entails lower taxes and fewer government regulations characterizing the economy. He asserts that sustained and gradual increases in economic freedom positively influence equality and income growth within the nation.

Scully echoes much of Berggren's doctrine. He found that the amount of economic freedom increases the rate of economic progress. He further contends that economic freedom is a positive and significant macroeconomic determinant of growth and holds that greater liberties and pronounced economic freedom reduce income inequality. This is done by increasing the share of market income going to the two lowest income quintiles and lowering the share received by the highest quintile.

Farr, et al. (1998) and Gwartney and Lawson (2003) further contend that economies with higher levels of economic freedom report larger per capita incomes and higher rates of economic growth. Other notable studies examine the relationship between the degree of economic freedom and other social-economic matters ranging from human migration, health issues and even the composition of governmental forms. Melkumian (2004), Ayal and Karras (1998, Dawson (1998) and Zaleski (1999) all weigh in on the impact of varying degrees of economic freedom. Generally, it is agreed that elevated levels of economic liberty are associated with desirable social and economic results. Within some of these studies there still remains considerable doubt as to the nature of the impact on income distribution.

Carter (2006) contends that the relationship between economic freedom and income inequality is positive, statistically significant and relatively inelastic. He disputes Berggren's interpretation of his own findings. Instead, using Berggren's results, Carter concludes that while the short run effect of greater freedom is to promote greater equality in income distribution, over the long run, this is simply not the case over a longer period of time. Greater freedom, he contends, will ultimately lead to greater measures of income inequality.

Bergh and Nilsson (2010) conclude that in countries enjoying greater international trade, pronounced levels of inequality are observed. Further, reforms toward economic freedom seem to increase inequality, especially in richer countries. It can be seen from this brief discussion that there prevails a certain degree of confusion and uncertainty as to the true nature of the relationship between economic freedom and meaningful social and economic measures. De Haan and Strum (2000) add to the confusion by reporting that there prevails a noted level of ambiguity as to the impact of economic freedom. They offer the conclusion that a pronounced relationship can be found based on certain measures of economic freedom while other indicators showed no relationship at all.

It should be noted that the above studies are international in scope and pertain to a comparison among nations. Much less investigation has been devoted to these important matters as they relate to the United States. Given this unfortunate dearth and the prevailing discord noted above, it appears clear that an examination of the impact of economic freedom within the 50 U.S. states is called for. Fortunately, the annual report of the Economic Freedom of North America noted allows for this all-important pursuit.

\section{METHODOLOGY}

The designed purpose of this paper is to examine the relationship between the degrees of economic freedom and the extent of income equality, or its absence, within the 50 U.S. states. The measure of economic freedom is taken from the Economic Freedom of North America Annual Report provided by the Fraser Institute. The Gini coefficient is used as the gauge of income equality. The Gini index, developed by the Italian statistician Corraodo Gini in his 1912 paper, "Variabilità e mutabilità, ("Variability and Mutability") is the standard measure commonly used to reflect income inequality within an economic community. The data used in this study were taken from ttp://en.wikipedia.org/wiki/List_of_U.S._states_by_Gini_coefficient 
Selected control variables are also incorporated into the model to perform their standard functions. These variables include the percentage of the population 25 years old and older who have earned a college degree. These data were taken from the tables provided by the Census Bureau. This measure is often included in such a model as a standard control variables (Compton, et al., 2011).

A second variable provided by the Bureau of Economic Analysis commonly used in studies of this nature is the initial real per capita income (Garofalo, et al., 2002). This provides a base for comparisons of changes over the time period under examination. A more accurate measure of the impact of the explanatory variables can be attained in this manner by accounting for the original position from which the observation began.

The Bureau of Labor Statistics of the US Department of Labor provides data measuring the percentage of states' economic activity devoted to agriculture and to manufacturing activities. It can be argued that economic conditions, including those pertaining to income distribution, might be measurably impacted by the industrial structure characterizing a state or national region. Therefore, some recognition should be given to the economic composition of each state.

Finally, the impact of state-wide tax policies must be considered. To accomplish this task, median property tax rates for each state are used in the model along with the lowest income tax bracket and the highest income tax bracket.

The time period under consideration is 2001 to 2010. Unfortunately, this timeframe incorporates some years not considered typical and exhibit abnormal conditions. Nevertheless, using the most recent data will provide a better account of the current relationship between the presence of economic freedom and its association with income distribution.

The variables used in the estimation process are shown in Table 2. A brief description is offered for each variable.

Table 2 - Description of the Variables

\begin{tabular}{|l|l|}
\hline Gini 2001 & The Gini index in each state in 2001 \\
\hline Gini 2010 & The Gini index in each state in 2010 \\
\hline EFI 2001 & The economic freedom index in each state in 2001 \\
\hline EFI 2010 & The economic freedom index in each state in 2010 \\
\hline CHG IN GINI & The change in the Gini index from 2001 to 2010 \\
\hline CHG IN EFI & The change in the economic freedom index from 2001 to 2010 \\
\hline GMCHG IN GINI & The geometric mean change in the Gini from 2001 to 2010 \\
\hline GMCHG IN EFI & The geometric mean change in the economic freedom index from 2001 to 2010 \\
\hline Property Tax & The property tax rate in each state in 2001 \\
\hline Low Income Tax & The lowest income tax bracket in each state in 2001 \\
\hline High Income Tax & The highest income tax bracket in each state in 2001 \\
\hline Percent With Degrees & The percentage of residents in each state with a college degree \\
\hline PercentAgri & The percentage of the state's economic activity contributed by agriculture \\
\hline PerMft & The percentage of the state's economic activity contributed by manufacturing \\
\hline
\end{tabular}

Standard OLS procedures are used to estimate the models. The response variable is the Gini coefficient and changes in the Gini coefficient over the time period in question. The absolute value of the coefficient, the absolute change in the coefficient and the geometric mean change are all used as response variables. The change in the coefficient, rather than the coefficient itself, is used in order to measure how income distribution might change based on levels of economic freedom with in each state. Identical measures for the economic freedom index provide the corresponding regressors. The absolute values of the control variables at the initial stage of the time period under consideration are incorporated into the model. 
The model can generally be expressed as

$$
\Delta \operatorname{Gini}_{i}=\beta_{0}+\Delta E F I_{i}+\sum_{i=1}^{50} X_{i}+\epsilon_{i}
$$

where $\quad \Delta$ Gini $_{\mathrm{i}}$ is the Gini coefficient for each state

$\Delta \mathrm{EFI}_{\mathrm{i}}$ is the economic freedom index for each state

$\Sigma \mathrm{X}_{\mathrm{i}}$ is the array of control variables for each state

A second model specification employs the geometric mean change in both variables. This procedure will account for any lag features that may inherently prevail in the relationship and negate the need for a distributed lagged model. The geometric mean is the appropriate way to determine the average percentage change over time in any time-series variable. It is found as

$$
G M=\sqrt[n-1]{\frac{\text { Last Value }}{\text { First Value }}}-1
$$

That is, it is calculated as the $\mathrm{n}-1$ root of the ratio of the most recent value to the earliest value. Subtracting 1 provides the percentage change. Thus, we have

$$
G M \Delta \operatorname{Gini}_{i}=\beta_{0}+G M \Delta E F I_{i}+\sum_{i=1}^{50} X_{i}+\varepsilon_{i}
$$

Finally, a standard, simple regression model is also estimated. This will reflect a more direct relationship between prevailing economic liberties and income dispersion. This model is estimated for both extremes of the $2001-2010$ time period thereby providing a means of comparing the relationship over the most recent decade.

\section{EMPIRICAL RESULTS}

Only scattered research has been offered as to the relationship between economic freedom and income distribution based on an examination of the U.S. states. As noted above, more attention has been devoted to international comparisons. A study focused on a single nation restricts the latitude available to the researcher. Several considerations that must be made in a multi-national basis are simply not pertinent when the focus is restricted to one country. For example, while the monetary structure and soundness of the currency may vary among different nations, this factor is of no consideration when a single country is examined. Judicial and political concerns are not as variant within a given civic or constitutional geographical range as they might be across international borders. Further, bureaucratic and legislative issues are more fixed within the confines of a single federal or social order.

These constraints imposed certain restrictions on the models that might be tested - thus, the model specifications noted in the previous section. Table 3 contains the results of the regression models noted above.

The response variable is the Gini coefficient and two forms of change in the coefficient are used as the measure of income equality. The economic freedom index is the primary regressor of interest.

Before interpreting the results it must be kept in mind that the Gini coefficient is constructed in such a manner that the higher the coefficient, the greater the degree of inequality. Conversely, higher levels of the economic freedom index denote greater freedom. Therefore, if a positive relationship is expected between economic freedom and greater equality, the correlation should be negative. That is, as the level of economic freedom within a state rises, its Gini coefficient should decrease evidencing greater income equality. 
Various regression models were estimated in the effort to identify a relationship between measures of income distribution based on the Gini index and measures of the levels of economic freedom among the 50 U.S. states. The results of the three regression specifications are reported in Table 3. In each case the response variables are the Gini coefficient in 2010 (GINI2010), the absolute change in the Gini coefficient from 2000 to 2010 (CHGGINI) and the geometric change in the Gini from 2000 to 2010 (GMCHGGINI).

Table 3 - Regression Results: p-Values in Parentheses

\begin{tabular}{|c|c|c|c|c|}
\hline Dependent Variables & \multicolumn{2}{|c|}{ GINI 2010} & CHGGINI & GMCHGGINI \\
\hline Constant & $\begin{array}{l}0.447 \\
(0.00)\end{array}$ & $\begin{array}{c}0.45 \\
(0.00) \\
\end{array}$ & $\begin{array}{l}-0.005 \\
(0.87) \\
\end{array}$ & $\begin{array}{l}-0.01 \\
(0.19) \\
\end{array}$ \\
\hline EFI 2001 & & $\begin{array}{l}0.007 \\
(0.26) \\
\end{array}$ & $\begin{array}{c}-0.042 \\
(0.065) \\
\end{array}$ & $\begin{array}{c}0.002 \\
(0.015) \\
\end{array}$ \\
\hline EFI 2010 & & $\begin{array}{l}0.006 \\
(0.42) \\
\end{array}$ & $\begin{array}{l}0.003 \\
(0.07) \\
\end{array}$ & $\begin{array}{c}0.00 \\
(0.138) \\
\end{array}$ \\
\hline CHG IN EFI & $\begin{array}{l}-0.0118 \\
(0.063) \\
\end{array}$ & $\begin{array}{l}0.006 \\
(0.35) \\
\end{array}$ & $\begin{array}{l}0.004 \\
(0.22) \\
\end{array}$ & \\
\hline GMCHG IN EFI & & $\begin{array}{c}0.04 \\
(0.65) \\
\end{array}$ & & $\begin{array}{c}-0.003 \\
(0.745) \\
\end{array}$ \\
\hline Property Tax & & $\begin{array}{c}0.07 \\
(0.28) \\
\end{array}$ & $\begin{array}{l}-0.09 \\
(0.65) \\
\end{array}$ & $\begin{array}{c}0.107 \\
(0.075) \\
\end{array}$ \\
\hline Low Tax Rate & & $\begin{array}{c}0.05 \\
(0.47) \\
\end{array}$ & $\begin{array}{l}-0.09 \\
(0.06) \\
\end{array}$ & $\begin{array}{c}0.026 \\
(0.077) \\
\end{array}$ \\
\hline High Tax Rate & & NA & NA & NA \\
\hline Percent With Degrees & & $\begin{array}{l}0.042 \\
(0.35)\end{array}$ & $\begin{array}{l}-0.04 \\
(0.27)\end{array}$ & $\begin{array}{l}0.058 \\
(0.24)\end{array}$ \\
\hline $\mathrm{R}^{2} / \bar{R}^{2}$ & 0.26 & 0.13 & 0.08 & 0.36 \\
\hline
\end{tabular}

Only the first model shown in Table 3 reports any significance between the Gini coefficient and measures of economic freedom. Specifically, the bivariate model using changes in the economic freedom index to explain Gini coefficients in the final year of the time period in question. Noteworthy is the fact that the coefficient carries the expected sign. The negative value clearly indicates that an inverse relationship exists between absolute changes in the index over the time period under study and the subsequent Gini index in 2010. That is, as the level of economic freedom increases the degree of income inequality is reduced. However, the other model specifications fail to identify any significant relationships.

This is in direct contrast to some earlier studies. The Ashby and Sobel paper noted above reported significant and persistent correlations between the index and income distribution. However, it should be noted that their model used income quintiles to compartmentalize ordered income levels. This in itself may account for the divergent findings. Garrett and Rhine (2011) reported that states' freedom indices are positively associated with rates of employment growth. But here again we find that the focus of their paper is not directed toward income distribution but pertain to employment levels.

It would seem that findings are highly sensitive to the manner in which income equality is measured. This study, like that offered by Carter (2006), relied on the Gini coefficient to demarcate income levels. In doing so, both studies found little or no relationship between levels of economic freedom and the manner in which incomes are distributed.

\section{SUMMARY AND CONCLUSIONS}

Economic freedom can have opposing impacts on the income equality. On the one hand, it can increase equality by removing restrictions and constraints on economic pursuits. Everyone is given the opportunity to apply their market talents in the effort to achieve economic success. However, not everyone enjoys the same degree of commercial acumen. Thus, despite the opportunities freedom might offer incomes may still be substantially skewed due to variations in individuals' innate abilities and motivation. 
On the other hand, a reduction in economic freedom permits the pursuit of social programs that tend to favor the economically disadvantaged. Through taxation and transfer central authority can elevate the relative position of certain legally and politically favored groups. This tends to promote a more egalitarian society in which incomes are more evenly distributed. Thus, equality is more likely to be fostered by centralized programs that restrict economic freedom. The question becomes which impact dominates. Is society more likely to approach a greater degree of homogeneity given open markets and free-range opportunities, or does equality require centralized direction?

While some of the earlier studies have found that states with greater economic liberty report positive economic consequences, this paper calls into question that contention. It may be concluded that the results depend heavily on how income and income distribution are measured.

Obviously, continued research in this area is called for. The unequivocal importance attached to these two critical economic concerns offers strong argument that further investigation is essential. Only through a complete and in-depth understanding of the matters surrounding the relationship between economic freedom can important to economic policy questions be addressed.

\section{AUTHOR INFORMATION}

Allen L Webster, Ph.D., Department of Finance and Quantitative Methods, Foster College of Business, Bradley University, Peoria, IL 61625 USA. E-mail: $\underline{\text { alw@ bradley.edu }}$

\section{REFERENCES}

1. Ayal, E and Karras, G. (1998) Components of Economic Freedom and Growth: An Empirical Study. The Journal of Developing Areas, pp $327-338$.

2. Bueno, A, Ashby, N and McMahon, F. (2012). Economic Freedom of North America; Fraser Institute: Vancouver Canada

3. Berggren, N (September 1999). Economic Freedom and Equality: Friends or Foes; Public Choice. pp 203 -223 .

4. Carter, J. (2006) An Empirical Note on Economic Freedom and Income Inequality; Public Choice, pp 163177.

5. Compton, R, Giedeman, D and Hoover, G. (2011) Panel Evidence on Economic Freedom and Growth in the United States; European Journal of Political Economy, pp 423-35.

6. Dawson, J. (1998) Institutions, Investment, and Growth: New Cross-Country and Panel Data Evidence. Economic Inquiry, pp $603-619$. He

7. De Hann, J and Strum, J (2000) On the Relationship between Economic Freedom and Economic Growth, Journal of Political Economy, pp 547-63.

8. Farr, W, Lord, R and Wolfenbarger, J. Economic Freedom, Political Freedom, and Economic WellBeing:A Causality Analysis. Cato Journal, pp 247-62.

9. Garrett, T and Rhine, R. (January, 2011) Economic Freedom and Employment Growth in the US States; Federal Reserve Bank of St. Louis Review, pp 1-18.

10. Gwartney, J and Lawson, R. (2003). The Concept and Measurement of Economic Freedom. European Journal of Political Economy, pp 405-30.

11. Melkumian, A. (2004) A Gravity Model Of Legal Migration to the United States; Unpublished Manuscript, Western Illinois University. 
NOTES 